\title{
Height Estimation Using Arm Span and Hand Length Measurements
}

\author{
Satyal $B^{1}$, Poudel $A^{1}$
}

\begin{abstract}
Introduction: Arm span and hand length can be used for the estimation of an individual stature. Arm span, hand length, foot length, head circumference etc. have been proved to be useful to correctly estimate the height of a person. It can be useful in various medico legal purposes. Objectives: The present study was undertaken to find the correlation between the arm-span and hand length with the standing height of both males and females and to derive regression equations for estimation of their height. Materials and Method: This cross sectional type of descriptive study was carried out with a total number of 200 Nepalese medical students consisting of 120 male and 80 female aged between 18 to 24 years. Stature, arm span and hand length were measured directly from the subjects by using anthropometric technique by a measuring tape and a spreading caliper. The data taken were statistically analyzed by computation. The relationship between body height, arm span and hand length were determined using simple correlation coefficients. Result and Conclusion: In this study, the correlation between the arm-span and hand length with the standing height of both males and females was found to be an accurate predictor of the height and regression formulae were derived for calculating the height of male or female with the arm-span and hand length.
\end{abstract}

Key words: Arm span, anthropometric measurements

\section{INTRODUCTION}

Anthropometry is the science of obtaining systematic measurements of the human body. Anthropometric measurements have been used historically as a means to associate racial, cultural, and psychological attributes with physical properties. Specifically, anthropomorphic measurements involve the size (e.g., height, weight), structure (e.g., sitting vs. standing height, shoulder and hip width, arm/leg length, and neck circumference), and composition (e.g., percentage of body fat, water content, and lean body mass) of humans. Stature is one of the major characteristics which have been employed in identification for medico-legal purpose.

Estimation of height is an important and primary factor to establish the identity of a person. Several studies have reported the effectiveness of using various body parameters in predicting body height ${ }^{1,2,3}$. The association of arm span and height was found to vary from race to race ${ }^{4,5}$.

Even though several studies of this nature are available on western and Indian population but very limited data are available on Nepalese population. The aim of this study was to

1. Mr. Biswas Satyal

2. Mr. Abhishek Poudel

Address for correspondence:

Mr. Biswas Satyal

Department of Anatomy

Nepalgunj Medical College

Chisapani, Banke, Nepal

Email: reply2belief@gmail.com find the correlation between the arm-span and hand length with the standing height of both males and females and to derive regression equations for estimation of the height of male or female in Nepali population.

\section{MATERIAL AND METHODS}

The study was cross sectional in nature. The study was carried out on 120 male and 80 female medical students of Nepalgunj Medical College, Banke, Nepal throughout the period of three weeks in the month of November 2017. The population was randomly selected to be included in this study. Their age ranged between 18 to 24 years. Prior to taking measurement of student, their informed verbal consent and permission from Head of department was taken.

The standing height, arm span and hand length were measured for all subjects. Subjects possessing skeletal deformities, physical disabilities, past history of skeletal injuries or diseases affecting bones and joints and subjects who are on any form of hormonal medications were excluded from the study. The subjects were said to stand with their heel together and her backs straight as possible so that her heels, buttocks, shoulders and the head touched the wall. The arms were hung freely by the sides with the palm facing the thighs. After asking the subject to take a deep breath and holding it, a measuring scale (steel plate) was placed against the head and wall to determine maximum height on the wall, and this was marked. The subject was then told to breathe and to step away from the wall. The height was then measured from the floor to the mark on the wall with steel tape which represents the stature in centimeters to the nearest 0.1 centimeters. Arm span was measured with a flexible steel tape from the tip of the middle finger on one hand to the tip of the middle finger on the other hand with the 
individual standing with her back to the wall with both arms abducted to $90^{\circ}$, the elbows and wrists extended and the palms facing directly forward. Hand length was measured as a direct distance from the level of tip of the most distal point on the styloid process of the radius to the tip of the middle finger by using the spreading caliper. The hand length was taken by asking the subject to place the hand on a table with the fingers together and thumb abducted. Readings were taken to the nearest 0.1 centimeters. Each subject was measured twice. When the two measurements for each parameter agreed within 0.4 centimeters, their average was taken as the best estimate for the true value. When the two initial measures did not satisfy the 0.4 centimeters criterion, two additional determinations were made and the mean of the closest records was used as the best estimate.

\section{RESULTS}

Regression equations using both hand lengths and arm span were formulated in order to estimate the height of a person (Table I).

By using these regression equations, height of the individual subject was calculated by using the arm-span and the handlength measurements. This calculated height was then compared with the actual height of the individual and the standard deviation was found as shown in Table II and III.

\section{DISCUSSION}

Time and again many authors have made their effort to estimate height through different physical measurements. Mitchell used arm length to estimate the height ${ }^{3}$, while Chumlea estimated stature from knee height ${ }^{6}$. Steele and Chenier in a study on black and white women in the age group 35-89 reported correlations of arm span and height of 0.852 and 0.903 for black and white women, respectively. All the previous studies use any one physical parameter to determine the height. Here we have used two physical parameters to estimate the height of person using both the upper limbs.

In present study, correlation coefficient between height and arm span and right hand length is 0.899 and equals for left hand too in males. Correlation coefficient between height and arm span and right hand length is 0.907 whereas same using left hand is 0.904 in females. The correlation values both in males

\begin{tabular}{|c|c|c|c|c|}
\hline Sex & Side & $\begin{array}{l}\text { Correlation } \\
\text { coefficient }\end{array}$ & $\begin{array}{c}\text { Regression } \\
\text { equation }\end{array}$ & p-value \\
\hline \multirow{2}{*}{ Male } & Right hand & 0.899 & $\mathrm{HT}=33.84+(0.68) \mathrm{AS}+(0.95) \mathrm{HL}$ & \multirow{2}{*}{$<0.05$} \\
\hline & Left hand & 0.899 & $\mathrm{HT}=33.40+(0.65) \mathrm{AS}+(1.01) \mathrm{HL}$ & \\
\hline \multirow{2}{*}{ Female } & Right hand & 0.907 & $\mathrm{HT}=26.53+(0.67) \mathrm{AS}+(1.43) \mathrm{HL}$ & \multirow{2}{*}{$<0.05$} \\
\hline & Left hand & 0.904 & $\mathrm{HT}=26.37+(0.68) \mathrm{AS}+(1.33) \mathrm{HL}$ & \\
\hline
\end{tabular}

HT- Height, AS- Arm span, HL- Hand length

Table I: Correlation coefficients and regression equations for estimation of height from arm span and hand length

\begin{tabular}{|c|c|c|c|c|}
\hline \multirow{2}{*}{ Variable } & \multicolumn{2}{|c|}{ Estimated stature (cm) } & \multicolumn{2}{c|}{ Measured stature (cm) } \\
\cline { 2 - 3 } & Range & Mean \pm SD & Range & Mean \pm SD \\
\hline Arm span and Right hand & $153.1-186.2$ & $170.04 \pm 6.29$ & \multirow{2}{*}{$154.1-186$} & $169.95 \pm 6.9$ \\
\hline Arm span and Left hand & $149.0-181.0$ & $165.62 \pm 6.09$ & \\
\hline
\end{tabular}

Table II: Comparison of estimated stature with measured stature from arm span and hand length in males

\begin{tabular}{|c|c|c|c|c|}
\hline \multirow{2}{*}{ Variable } & \multicolumn{2}{|c|}{ Estimated stature (cm) } & \multicolumn{2}{c|}{ Measured stature (cm) } \\
\cline { 2 - 3 } & Range & Mean \pm SD & Range & Mean \pm SD \\
\hline Arm span and Right hand & $143.7-166.6$ & $156.76 \pm 5.68$ & \multirow{2}{*}{$154.1-186$} & \multirow{2}{*}{$169.95 \pm 6.9$} \\
\hline Arm span and Left hand & $143.4-166.3$ & $156.39 \pm 5.65$ & \\
\hline
\end{tabular}

Table III: Comparison of estimated stature with measured stature from arm span and hand length in females 
and females are statistically significant. In the present study, the equations derived from arms span and right hand length for male and female subjects are $33.84+(0.68)$ Arm span $+(0.95)$ Hand length and $26.53+(0.67)$ Arm span + (1.43) Hand length, respectively. The equations derived from arm span and left hand length for male and female subjects are $33.40+(0.65)$ Arm span + (1.01) Hand length and $26.37+(0.68)$ Arm span + (1.33) Hand length respectively. The derived equations were tested and the difference between measured and estimated height was found to be non-significant.

A similar study carried out in Gujarati population also attempted to formulate regression equation showing correlation coefficient between height and arm span and right hand length to be 0.803 and for left hand to be 0.802 in males. Correlation coefficient between height and arm span and right hand length was shown to be 0.868 and same using left hand was 0.869 in females ${ }^{7}$.

Another study done in Birgunj population also suggest arm span measure to be a reliable indirect anthropometric measurement for estimating body height in adults ${ }^{8}$.

\section{CONCLUSION}

Arm span and hand length measurements can be a useful tool to determine the stature of an individual. This can be proven beneficial in various medico legal purposes. A very few studies have been done in this field. The present study is limited within its limited number of sample. A thorough study with larger number of population is necessary to gain more precision in such task. It is necessary to develop separate models for each population, on account of ethnic differences, using bigger samples for the prediction of body height utilizing arm span measurement. A more precise estimation of the average body height and its prediction utilizing arm span and hand length measurements in Nepalese adults would require a larger sample with sufficient geographical and social heterogeneity or a national survey that measures the whole population.

\section{REFERENCES}

1. Jalzem PF, Gledhill RB. Predicting height from arm measurements. J Pediatr Orthop 1993;13(6):761-5.

2. Yun DJ, Yun DK, Chang YY, Lim SW, Lee MK, Kim SY. Correlations among height, leg length and arm span in growing Korean children. Ann Hum Biol 1995;22(5):443-58.

3. Mitchell CO, Lipschitz DA. Arm length measurement as an alternative to height in nutritional assessment of the elderly. J Parenter Enteral Nutr 1982;6:226.

4. Steele MF,Chenier TC.Arm-span, height, and age in black and white women. AnnHumBiol 1990;17(6):533-41.

5. Sathyavathi K, Agarwal KN, Rao NSN, Reddy P R. Arm-span and height measurement during adolescence. Ind Pediatr 1979;14(10):839-47.

6. Chumlea WC, Roche AE, Steinbearagh ML. Estimating stature from knee height for persons 60 to 90 years of age. J Am Geri Soc 1985;33:116-20.

7. Malli MS, Vyas BM, Gosai P, Gupta S. Estimation of height of the person by using arm span and hand length measurement. J Med Gujarat 2015;70(1):105-7.

8. Sah RP, Kumar A, Bhaskar RK. Body height and its estimation utilizing arm span measurements in population of Birgunj area of Nepal: an anthropometric study. J Col Med Sci Nep 2013;9(4):9-14. 